\title{
Marketing Strategy Implications of Employee Brand Engagement: Optimism and Commonality: An Abstract
}

\author{
Christine Pitt, Pierre Berthon, Ian Cross, Val Hooper, and Joao Ferreira
}

\begin{abstract}
This paper looks at brand engagement in the context of employees and B2B firms, two areas that are largely overlooked in the extant brand engagement literature. Using the results from a large-scale study of employee brand engagement in social media, two key drivers of employee brand engagement are identified using the content analysis tool, DICTION, namely, optimism and commonality. Employees of top-ranked and top-rated firms express higher levels of optimism and commonality in their reviews of their employers on social media. This allows the construction of a $2 \times 2$ matrix that allows managers to diagnose strategies for increasing or improving employee brand engagement. This creates four different kinds of employee brand engagement situations and offers human resource and marketing managers different strategies in each case. This paper demonstrates how practitioners and scholars can shed new light on how stakeholders engage with brands.
\end{abstract}

References Available Upon Request

C. Pitt $(\bowtie)$

Royal Institute of Technology, Stockholm, Sweden

e-mail: christinepitt91@gmail.com

P. Berthon · I. Cross

Bentley University, Boston, MA, USA

e-mail: pberthon@bentley.edu; icross@bentley.edu

V. Hooper

Victoria University of Wellington, Wellington, New Zealand

e-mail: val.hooper@vuw.ac.nz

J. Ferreira

University of Beira Interior, Covilhã, Portugal

e-mail: jjmf66@gmail.com 